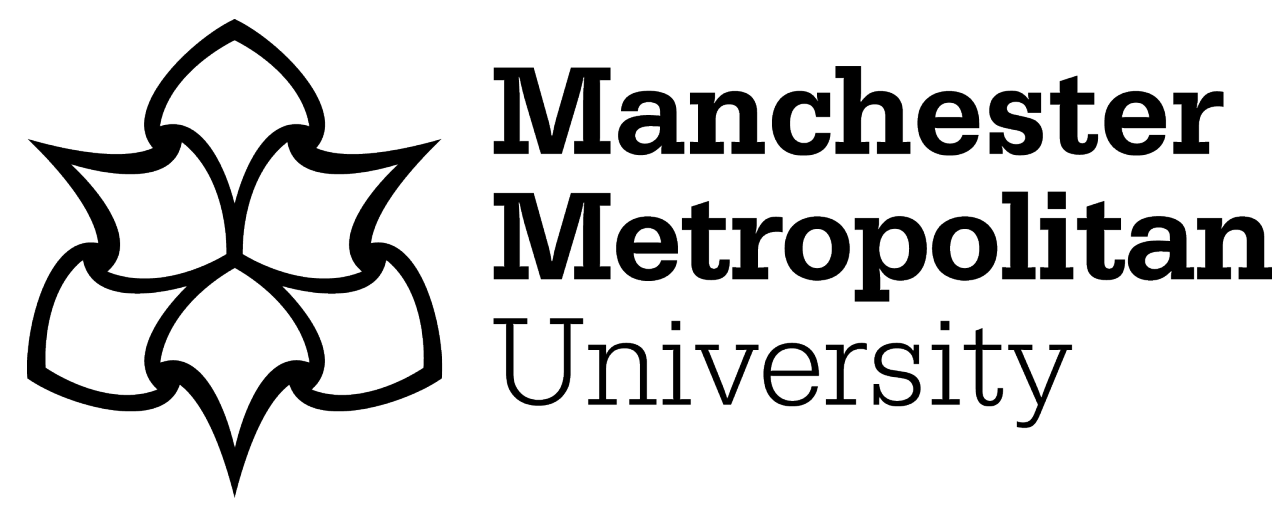

Cocchiarella, FN, Vargas, V, Titterington, S and Hayley, D (2017) Research informed sustainable development through art and design pedagogic practices. In: Implementing sustainability in the curriculum of universities : approaches, methods and projects. Springer, Cham, pp. 207-221. ISBN 9783319702803

Downloaded from: https://e-space.mmu.ac.uk/620982/

Publisher: Springer, Cham

DOI: https://doi.org/10.1007/978-3-319-70281-0_13

Please cite the published version 


\title{
Research Informed Sustainable Development Through Art and Design Pedagogic Practices
}

\author{
Authors: \\ Fabrizio Cocchiarella \\ Manchester Metropolitan University, Manchester, UK \\ Email: f.cocchiarella@mmu.ac.uk \\ Valeria Vargas \\ Manchester Metropolitan University, Manchester, UK \\ Email: v.vargas@mmu.ac.uk \\ Sally Titterington \\ Manchester Metropolitan University, Manchester, UK \\ Email: s.titterington@mmu.ac.uk \\ Dr David Haley \\ Email: davidhaley@yahoo.com
}

Keywords Education, Sustainable Development, Futures Thinking, Art \& Design, Salon, Capable Futures, Landscape

\begin{abstract}
This paper explores a pedagogic case study, which embeds academic research activity into a masters level unit of study. Students were invited to work alongside the LiFE 'Living in Future Ecologies' research group at Manchester School of Art to collaboratively investigate themes for sustainable development within a city context. Pomona Island, a brownfield site on the boarders of Manchester, Salford and Trafford presented a context for complex issues of local government, and questions of international relevance on resilience and responsible urban planning. Through learning about the landscape and sensitive ecology of the island, students and researchers explored notions of context, climate, visions for future living, the opportunities and the responsibility of art and design practices in steering social reasoning within a neoliberal system.

This paper presents a carefully considered enquiry-based framework, analysing academic questioning that has enabled the transformation of the ephemeral and immaterial into a methodology to address misguided political agendas. The paper articulates the different methods used to embed research practice in the learning environment. This type of project also fully illustrates innovative learning and teaching methods as ways in which art and design practices can uniquely engage with and stimulate thinking to influence and nurture change. Through presenting responses from a psychogeographical walk for Manchester European City of Science in July 2016, a conversational, transformative tool
\end{abstract}


for learning was developed. Reflections on the project further evaluate the multidisciplinary interpretations, already collated in a collaborative publication with the Pomona community and publisher Gaia Project.

\section{Introduction}

The LiFE Professional Platforms unit ran from March to September 2016. It invited Masters students at Manchester School of Art, across a spectrum of creative disciplines, to engage with the research group. This supportive sharing community, investigated ways of shifting the way we think and create visions for the future through ecological arts and design practices based on sustainable development principles at a professional level. The reasoning for merging research culture with postgraduate study was that students could learn important professional methods through working with and alongside research professionals. The cultures of practice have similarities so rather than mirror each other as tutor and student the interaction was more as master and apprentice and as the apprentice becomes more skilled, knowledgeable and flexible, they become more embedded within the 'professional team.' The intention was to utilize the different experience levels and social lenses into a way in which to re-evaluate, re-position and explore important mutual issues. From a power perspective, this initiative permitted a more rihzomatic approach, allowing the 'professional' researchers/teachers to learn from the learners what the learners need to learn. In this way, a learning dialogue was formed that focused on the topic of learning and the means by which all parties might learn and benefit (Deleuze \& Guattari 2014; Haley 2017a).

The LiFE (Living in Future Ecologies) research group was formed a year earlier and is a cross-faculty collaborative group of researchers seeking to intervene in the sustainability discourse to propose innovative responses to climate change and design future scenarios in which to implement 'capable futures' (Haley, 2008). The group's main focus areas are around waste, biodiversity, urban food production, future lifestyles and how these interrelate to create a circular economy. The group also runs occasional events called 'Opiso' derived from the ancient Greek word, which means behind or back, but refers not to the past but to the future. Early Greek imagination envisaged the past and the present as in front of us, something that we can see. The future was viewed as invisible, meaning that we are walking blind, backwards into the future. (Knox, 1994)

These events became think tanks, sandpits and salons in which to showcase futures thinking initiatives and to expand and explore specific future living issues. MA students were invited to take part either individually or collectively to identify an issue that related to or evolved from current LiFE group thinking. The students were supported by researchers with professional experience and expertise in design, art, space, architecture, anthropology, psychology, ecology, environmental policy and education for sustainable development. Students acquired skills that enabled them to tackle the theoretical and the physical, thereby materializing their thinking through artefacts and practical applications in which to propose possible alternative futures. By embedding research methods in the discourse between students and researchers, students became more confident and lateral 
thinkers. Ideas and theories carried more meaning through a shared collegiate urgency to respond and re-interpret opportunities. Students learnt how to position their thoughts and concepts more clearly as proposals for discussion with a knowledgeable community. This allowed students to explore ambitious creative applications for their work quickly and effectively. This, also gave members of staff the opportunity to 'play', improvise and invent beyond the curriculum, thereby joining students in the creative learning experience. In this way the LiFE research group was enabled to pursue its own agenda of seeking meaningful forms of inquiry and generate situations for transdisciplinarity to emerge (Nicolescu 2002).

As the students developed their questioning and thinking around LiFE issues the group was invited to respond to Pomona Island, a brownfield site between the Bridgewater and Manchester Ship canals, on the boarders of Manchester, Salford and Trafford. This presented an authentic context in which to deal with complex issues of local government, and questions of international relevance on resilience and responsible urban planning. Learning about the landscape through a series of talks and site visits the group collectively gained knowledge about the sensitive ecology of the Island. Through an enquiry-based approach to research and pedagogy, researchers and students synthesized information and context that emerged into new networks with local campaigners, artists, designers, film makers and ecologists who intervened in the planned development.

Pomona Island sits in a precarious situation, as the land is privately owned by one of the North of England's largest development companies, and it has strategic plans to develop city centre apartments rather than conserve sites of ecological importance. From an urban industrial residual space, deeply rooted in its historical and political context, Pomona has evolved new ecologies to become an important habitat for new species of plants and wildlife. The use of the site over many years has seen transitions from high industrial usage, as a main port connecting Manchester to the rest of the world, to a post-industrial wasteland. As the politics of place and the city changed it became an EU funded leisure facility. Then, as it again became an abandoned site, it became a paradise for nature and migrating birds who made Pomona their home.

Students and researchers responded to the proposed plans by developers with urgency. Art and Design practice here was seen as a way to intervene through imagining diverse futures for the island that could influence future development and present other alternatives to the insensitive systematic re-population of urban centres. Creative practice was used as a participatory, interdisciplinary and community-based process to investigate the appropriateness of potential solutions within a holistic context (Wahl, 2016). The group recognized their potential impact on future development plans that society needs to re-invent future habits, new ways of living in urban environments, and provide a framework for facilitating the many stakeholders involved - humans from all sectors, and other-than-humans, coexisting in the urban landscape.

Through the synthesis of an enquiry-based process, analysing academic questioning enabled the transformation of the ephemeral and immaterial into methods of intervention into misguided political agendas. Proposals from the group questioned the foundations 
for 'a sustainable society' and the word sustainable itself was questioned as a confusing term that embeds a notion of maintaining the 'status quo' rather than inventing a framework to develop future capability for change (Haley, 2016). Recognizing the problem that current city development often exploits and degrades local ecosystems, responses interrogated the notion of 'capable futures' as a means of inventing ways in which to foster shared abundance for collaboration and regeneration (Haley, 2008; Wahl, 2016). Students and researchers created new visions for Pomona and presented these responses during a psychogeographical walk for Manchester European City of Science in July 2016, as a conversational tool for transformative learning. The multi-disciplinary interpretations were collated in a collaborative publication with the Pomona community and publisher Gaia Project to provide a creative form of project evaluation.

\section{Collective Visioning}

The LiFE research group gave students on the MA Professional Platform unit the opportunity to study and engage with research group members, through weekly seminars that presented LiFE research interests and tutorial sessions. These also gave students the opportunity to present and discuss issues and themes that they were investigating in their own practice. Through an enquiry-based pedagogic framework that supported the students autonomy as independent and collaborative researchers (Sierens et al. 2009), the unit also allowed students to become core members of regular research group meetings to help direct and discuss agendas being developed. This allowed the researchers to adopt roles as mentors. Those with specialist expertise and experience were able to nurture and develop the evolving curiosity of the students (Cocchiarella, Booth. 2015).

At one of the research meetings, the group identified an opportunity to focus both their various enquiries around sustainability and their many disciplinary lenses on a more holistic project that would respond to Pomona Island as a real life situation. The collaborative nature of the project encouraged open dialogue through the dissemination of alternative visions for Pomona, which created the potential for cultural transformation.

By producing narratives that questioned the perceived 'unavoidable' future, conversation and collaboration helped to steer and create a move towards a more desirable co-created vision of a new regenerative culture. Re-positioning the responsibilities to maintain life within the biosphere rather than monetary economies, this shift in thinking allowed a more creative interpretation of how design for living needs to recognise and include the many stakeholders. With mutual respect, they may then negotiate a common ground between the developer, and community to prioritise co-existing in urban centres.

\section{Learning Undisciplined Behaviour}

In Higher Education, it seems that we have forgotten that sustainable development was devised as a response to climate change. Appropriated and applied to everything from financial viability to the growth of carbon industries, this ubiquitous phrase now, paradoxically, represents both the cure and the cause of our greatest concerns. The term 
sustainable development may indeed be a contributing factor in the wicked problem of climate change. Wicked problems often exacerbate the very situation they try to address. So educating people to sustain development provides us with a perfect paradox, perpetuated by ridged adherence to the disciplinary structures and strictures of higher education institutions and research councils. Indeed, most pleas for multi, inter and transdisciplinarity are misunderstood, misguided or highjacked by continuing Cartesian cognition and fortifying the silos of disciplinary dogma.

Perhaps, 'undisciplinarity' is required in Higher Education for students to become ecologically resilient for adaptation? (Haley, 2017) Indeed, this may be the point at which art and design are finally valued, because traditional research methods, alone, inadequately address these issues. This project practically demonstrated that the creative arts can, potentially, offer the 'leverage points' (Meadows 1999) to provide the transition from order to disorder, thesis to antithesis, and structure to process that may then evolve as organisation, synthesis and pattern (form) for a critically robust curriculum for sustainable development, or 'Capable Futures' (Haley 2008).

Despite our compelling myths to the contrary, the world and most things in it are beyond our control, so we must learn to expect the unexpected, the uncertain, the indeterminate. And to prepare for such eventualities is to be ecologically resilient.

While 'engineered resilience' refers to how fast a system returns to equilibrium after a shock or stress, the term 'ecological resilience' is applied to how far a system may be perturbed before it collapses or becomes another state of being (Walker, B. H., et al (2006). The capacity to withstand disturbance is not just a question of how long the status quo can be maintained, but how we might emerge into a new world. Of course resilience is both pattern and process. And like ecology and art and design can be understood as emergent phenomena, not purposive, solution-led, problem-based methods or objects that can be fixed. So, perhaps, we need to reinvent art for the next revolution of life? And to do this, maybe we need to create disorder (diversity) from order (monoculture) and pursue the antithesis of civilisation, to synthesise our evolution to a new form of organisation, or undisciplined, 'regenerative culture'? Instead of thinking of these initiatives as separate or conflicting interests, it may be even more useful to consider resilience as dynamic revolution/resolution - resolving duality - a process emerging from one state to the next. Together, disciplinarity and undisciplinarity, then offers education for sustainable development the ability to evolve to meet the challenges of a rapidly changing world (Haley 2017).

\section{Education for Sustainable Development}

This is the process of equipping students with the knowledge and understanding, skills and attributes needed to work and live in a way that safeguards environmental, social and economic wellbeing, both in the present and for future generations. (QAA, 2014). As in other processes of change there might be trends and shared experiences but at micro levels change varies according to the scenario and the people involved. At Manchester Metropolitan University there are policy frameworks that seek to support the integration 
of education for sustainable development in the university, probably due to variations in processes and culture between faculties or departments, there is a wide range of initiatives in this area. For instance, in the Art School, academics have worked towards embedding education for sustainable development into the curriculum through interdisciplinary and innovative approaches (e.g. Langdown and Vargas, 2015; Haley et al., 2016). These include cross-faculty (i.e. design, art, architecture) and cross-university (i.e. engineering and fashion) collaborations, however, these are individually (i.e. staff and students) led initiatives so far. In this scenario, the LiFE research group is a pivotal enterprise for the integration of sustainable development, presenting opportunities for the local community, students and staff to work at the same level.

To follow, the paper will describe one of the key moments at the start of the student-staff dialogue for the development of a collective approach in this project.

After a few months of working together academics invited students to join the LiFE group. Before the one-hour meeting started, students and staff found their places in the meeting space. As it may be expected, students sat at one side of the table whilst staff sat at the other side. The first half of the meeting was, what could be described as 'business as usual', staff engaged in discussion and students silently listening. However, mid-way through the meeting, the Chair suggested different sitting arrangements, mixing academics and students. The dynamics in the group as a whole changed with students and staff interacting more actively with each other.

One interpretation of this event might be that power dynamics were disturbed to bring about a more equal approach to dialogue. Subsequently, the dialogue was open to the Pomona community seeking to foster active involvement of all members, which is one of the key principles for an institutional process of change towards sustainable development (Tilbury et al., 2005).

In this project, an action learning conversational approach started to emerge in which members of the collective brought up their questions and challenges to reflect on them, and to develop their practice through the cycle (Marsick and Maltbia, 2009, p. 162):

- Framing of the challenge as a question.

- Unpacking meaning through sharing information about the context and prior action.

- Peer questioning (to which the problem holder does not immediately respond) to unlock mental models that make one blind to other points of view.

- Identifying assumptions that underlie current ways of framing the challenge

- Reframing one's understanding of the situation

- Making more informed decisions and taking informed action to address the challenge

As this approach was not imposed on staff, students or local community, it might be possible to suggest that this was collectively developed instead of directed by an individual. However, future empirical research may be needed to develop conclusions. 


\section{A Creative Journey}

The introduction to the subsequent book, 'Fruitful Futures: Imaging Pomona' included this statement about the Pomona Encounters walk for the Manchester European City of Science Festival:

The Art of Fruitful Living was a walk inspired by the ecology of food, the potential for urban food production and Pomona, the Roman goddess of fruit. The walk took twenty one participants on a creative journey through the habitats of Manchester, Salford and Trafford to encounter a cornucopia of paradoxical tales about biodiversity and urban planning, carbon-free air miles, invasive species for healthy living, and old toolkits to design new nature. The walk acted as a method for testing and collecting ideas as part of Manchester European City of Science.

Although a trial walk had been conducted the previous week, the event itself took much longer than expected, as participants added extra material to their performances and contributions. Like the pilgrims of Chaucer's Canterbury Tales, these walkers gained energy from the stories, anecdotes, polemics and information they presented. The route of the walk itself generated another source of energy. The changing environments came as quite a surprise to many of those who thought that Manchester's urban landscape was mono-cultural. However, the link between the intense retail malls, over-designed civic spaces, monumental historic buildings, drab Modernist dwellings, mundane contemporary housing and secret wild pathways was the River Irwell. Glimpses and full vistas of the river, its confluence with the River Medlock and transformation into the Bridgewater and Manchester Ship Canals provided regular refreshment. As noted by retired, Senior Lecturer at Manchester School of Art, architect and geomancer, David Ellis, the Irwell contributed to the use of ley lines adopted by the Romans and the Church to site important buildings in Manchester (Ellis \& Thomas 2001). The adoption of the river course both for this walk and in planning is, also, fundamental to Feng Shui, the ancient Chinese art/science/philosophy of harmonizing people and their environment. This form of Taoist ecology employs dragon lines, rather than the straight geometric lines of geomancy, and rivers play a very important part in this understanding of the interactions between natural and cultural phenomena. Both ley lines and dragon lines are known to align, attract and channel sources of energy. They may, also dissipate or dispel energy if not correctly related or attuned to.

However, the event permitted each walker, whatever their background, to bring their own research and interpretations to the walk, so in turn, all were experts, guides and followers. Similar to the ' $\mathrm{V}$ ' formation or skein of migrating birds, each walker led to provide the slip stream for others, and then allowed others to lead the way physically and metaphorically. For the six-hour duration of the walk, this process provided great comradery and feelings of fraternity amongst those who participated, contributing knowledge in the context of a shared experience. 


\section{Walking and talking as a transformative tool for learning}

Anderson (2004) suggests that talking whilst walking helps collaborative knowledge to emerge and that human identity is shaped through this practice by connecting the self with the outside (i.e. other humans, non-humans and the built environment). In addition, they suggest that 'places are not passive stages on which actions occur, rather they are the medium that impinge on, structure and facilitate these processes.' (2004, p. 255) Haley had also deployed these methods in his programme of eco-urban, art-walks, 'A Walk on the Wild Side' (2004-8). He had learned the value of this process from psychologist, Professor Judith Sixsmith, who used walking therapy as a less confrontational way for her clients to provide relaxed interviews (i.e. interviewer and interviewee share the same horizon).

Pomona was a platform for further development of action learning conversations, which started in the meetings and sessions that were part of the students curriculum. Creating a collective through balancing power relations provided a bottom up approach where members shared responsibilities and ownership of the project. This approach fostered positive engagement for staff, students and local community members who presented their projects on the walk.

Walking provided space and time to reflect. Small groups formed at the beginning and soon individuals would be moving from group to group discovering others' perspectives. Walkers would also have time and space to engage with Pomona Island's non-human communities through structured activities such as the design interviews to different species developed by Crystal Chan, MFA Design Cultures student. Other contributions that were presented in the walk and later published in the Fruitful Futures collective book included tales, fables, poems, drawings, food, designs and analyses of social and political urban planning.

Students and staff performances during the walk were linked to the place at a conceptual level and through embodied experience, which aimed at fostering longer periods of reflection and multi-dimensional project developments (Lakoff \& Johnson 1999). Walkers had the opportunity to explore their own identity, as well as that of the place, from varied perspectives engaging with the complexity of the interaction between human activity and nature. The temporal and spatial dimensions reinforced the context of the human identity exploration. People who knew Pomona island well from the three groups (i.e. staff, students and community) mainly provided the temporal dimension. The island, its inhabitants and the exchange of place related knowledge triggered by the walk, provided the spatial dimension.

Among the reasons that may suggest the success of the curriculum (i.e. unit and walk) and the potential for transformative learning through similar approaches include the following. Firstly, the engagement of students increased through the duration of the unit. Secondly, students engaged in this form of learning for the whole six-hour walk, which was probably the longest university session they had experienced. Thirdly, the 
interconnections that appeared through their conversations on the walk and through the whole unit of their course became more explicit in the writing process. In other words, the process of writing became a reflective continuation of the creative process.

\section{Co-Production}

Through the creation of the book, editors, publisher Gaia Project and graphics collective Textbook Studio joined the editors (Cocchiarella, Haley and Vargas) to co-curate and publish a limited edition of 250 books that acts as a platform to disseminate the work produced by the collaborative efforts of the research group, students and Pomona community. The book is the synthesis of creative reasoning that acts as an interface to intervene in the sustainability discourse. Through the printed publication the group were permitted to document its visions and disseminate these messages to the developer, local community and international networks, hopefully inspiring a transition in thinking and eliciting a change in mindsets to address local and global issues.

The launch of the book took the form of a Salon event as part of Design Manchester in October 2016. The event showcased responses to Pomona in an exhibition to inspire and elicit dialogue, discussion and debate. The Salon format is a platform in which to network, share vision, specialism and non-specialism in response to the work presented as a way to initiate new networks and generate new collaborative initiatives.

The precise history and function of the Salon is varied, however in this particular context it is a place to bring people together from many different backgrounds and disciplines to exchange thoughts and ideas. Salons originated in Ancient Greece and over the centuries spread across Europe. Through the Literary Salons of Denmark and King Stanislav of Poland's 'Thursday Dinners' to the French 18th Century Salons, they were places to facilitate discussion and debate on: science, philosophy, radical theories and political matters. These meetings contributed to fundamental political and cultural change, inciting Enlightenment Philosophies and the French Revolution (Goodman, 1994). There were also numerous salons held by women of various classes and some of the hostesses became very influential, which in turn played a seminal role in enabling women to be educated in politics, philosophy and play an active role in public life (Lougee, 1976).

Whilst not being new, the Salon is an instrumental platform that can be forever modern, as it can be refreshed with new content and fed with a diverse demographic of people, subject matter and ideas. In this case, The Salon style of presenting the work was adopted to gather people of various communities, disciplines, ages and walks of life, to discuss, debate, exchange, entertain/ be entertained and to think about LiFE.

The Salon also hosted a selection of work in response to the book by undergraduate students from BA(Hons) Three Dimensional Design, MA Landscape Architecture and Product Design students from ArtEz Institute for the Arts, Arnhem, Netherlands. Inspired by the MA Professional Platform project and facilitated by both researchers and MA students the 'Opiso City: Design Lab' project was a workshop based between Insitu (Architectural Salvage warehouse based in a Grade 11 Victorian pub), Phoenix House 
(wood, metal and ceramic studios) and Pomona Island.

The Salon showcased an ambient backdrop for discussion and debate amongst a multitude of exhibits; designed and found objects, film projections, a performance of specially composed music and poetry inspired by Pomona. The mapping of ideas on rolls of wallpaper from the workshops, printed posters from the book, flowers and vegetation from Pomona adorned the walls and were suspended from the ceiling to make up what was a rapid curation with a 1970's Punk feel to it. This was a spontaneous meeting of locals, Design Manchester festival patrons and all those involved in the content for the Salon and publication, which included students and staff, writers, artists, designers, educators, composers, poets, musicians, urban planners, zoologists, anthropologists, ecologists and filmmakers. It resembled a live, unrehearsed, unedited, unlimited, 3Dimensional mixed version of Facebook, Instagram, Pinterest, Skype, and Face Time, that existed outside the digital arena, in real time.

It was both energizing and stimulating to experience such a large number of people connected together under one roof. Since so many of these people were presenting thoughts and ideas at the same time, it meant that there was a guaranteed audience with potential for shared interest and support for each other. Being part of a group show also reduces the pressure of showing work as a solo artist/presenter while at the same time an audience is given choice and variety of content.

To see the speed in which non-technological communication can operate is refreshing, there is no copying, trash can, digital delay, rendering, spell check or cut and paste, it's a form of unscripted, spontaneous and unguarded interaction with no information or electrical feeds required. It was pure 'Living in the Moment' (Jenkins \& Deuze, 2008).

Art galleries, theatre and opera present work in a similar way to the Salon, however the Salon is more informal and its dynamic positively encourages dialogue and engagement between what is on show, the presenter(s) and the observer(s), in equal standing.

Ultimately, the Salon format is very flexible, it can operate within or outside conventional spaces, with or without; public funding, commercial constraints, challenges and commitments. There is the potential to have regular Salons that can continue to grow. There can be shifts in focus and emphasis, bespoke gatherings can be tailored to the needs of those showing a particular type of work to reach a specific size and type of audience. It's a form of market research, marketing, promotion, public relations, communications, networking in a relaxed and informal way and the audience can mix, add and take what they will. Connecting, collecting and collating information and meeting people in the moment in a space(s) of interest, face to face contacts made, for future Salons, for meetings and dialogues.

Future Salons will maintain existing connections and expand new networks, the more support and the greater numbers of people brought into the Salon arena to share, discuss and present ideas then the stronger the community can become. The Salon is a format that can happily coexist and develop in tandem with social media to reach an evergrowing audience, both digitally and in real time. Participants may become a live stream 
of future Facebook pages, but the present and the now is in reality, face to face, no screens and digital edits can divide the social experience (Keller \& Fay, 2012).

People and content from varying backgrounds and disciplines can be represented, unite and exchange simultaneously within singular or multiple locations, both locally and internationally. From this, we can look at expanding and sharing our connections and knowledge, so that theories, visions and philosophies explore existing ecologies in which to develop, inspire and support Living in Future Ecologies.

\section{Conclusion}

As part of Design Manchester, the 'collective power' of the participants were showcased through the publication and Salon event. Scenarios for change were published and exhibited as mediators for conversation, connection and the development of new networks between public, planners, community and education.

Through creative visioning, students, researchers and community investigated the tools in which to implement new scenarios for Pomona. Through this collaboration the philosophical reasoning for responses was underpinned by specialist knowledge that was strengthened by professional experience. Responses although mainly conceptual were still plausible and possible. The creative interpretation of Pomona Island was holistic of its contexts, which lead to a deeper level of response and understanding of the importance of the works produced. Through co-design (FaudeLuke, 2007), participants proposed visions of a new speculative future and how it could be achievable. These visions and responses re-interpreted the social, economic, political and ecological perspectives that were invested in the site. It was recognised that in order to implement many of the proposals there would need to be a move towards a bottom up, participatory democracy in which the community's voice is heard by the council, developer and planners. Furthermore, it was understood that in order to translate moral arguments of consensualism and evidence based realism (Batty, 2001) into political structures for action, proposals needed to inspire a strategy to enable a 'power of change' to the current development strategy.

The Pomona Island Professional Platform unit explored the way in which art and design thinking, through creative discourse, can act as a conduit to innovate systems thinking and imbue future scoping in an educational context through 'pervasive creativity' (Bohm and Peat, 2000). By asking students to critically analyse the social situation surrounding Pomona students learnt about local ecology, politics and social structures that shape the everyday. Through their participation in re-thinking and reinventing a possible future, education facilitated a subversive force in which to intervene and initiate a change in mindset (Freire, 1996).

Through futures thinking, art and design narratives generated by the unit in collaboration with the LiFE research group and local community, gave the 
opportunity to highlight social and political issues of how we choose to live in future cities, and provided the opportunity to make the public (localized audience) aware of capacities they already possess to elicit change and be more instrumental in developing socio-cultural capital (Head, 2016). This holistic involvement of the many stakeholders of Pomona Island, through a systems approach (Westley et al. 2002) to strategic design thinking, allowed a more clearly defined egalitarian connection between the city (human) and landscape (nature), as a way to address forward-looking behaviour in response to a Panarchical system of regional resource and ecosystem management (Gunderson \& Holling, 2002).

Students and researchers working collaboratively on research focused agendas provided a platform for experimentation with ways of working, seeing, doing and thinking. Limitations of the project were turning these proposals into real changes beyond the conceptual and into real alternative realities for the Island. Unfortunately, the local councils and developer who owns the Island, have other agendas that follow a different rule of priorities. However, it's through this kind of project that we are allowed to explore notions of what is desirable in terms of re-inventing the city. As well as being a valuable creative and academic exercise through the project we can start to signpost changes in neoliberal ideals used to justify 'progress' which fundamentally taste less appetizing in the growing illumination of context and climate. The project gave a holistic vision from a community with many different connections to the place that runs far deeper than shallow financial motivations. The project although not physically changing the fate of Pomona has been an invaluable force in bringing communities of people together to re-think and re-iterate what is important in the changing social, political, cultural and ecological places we call home. Indeed, this concept is at the route of the word ecology or 'oikos', that defined the design of an Ancient Greek home in its full familial, civic, environmental and cosmological contexts. And, as Gregory Bateson pointed out, ecology is 'the pattern that connects' (Bateson 2002).

Through conducting an imaginative transdisciplinary enquiry, investigations translated art \& science methods to establish new measures in which to contextualize and respond to the multi-layered landscape. The inquiry imagined the context of Pomona as a wicked problem (Brown et al. 2015). Utilizing the many approaches and perspectives of participants permitted everybody to learn from each other's knowledge and experience, in turn contributing to the new visioning and development of strategies for Pomona. The open nature of the enquiry allowed for transdisciplinarity through the many perspectives of design, landscape, planning, governance, resilience and socio-environmental agendas. The many perspectives brought a holistic overview to the project which meant that creative visions became multi-faceted and multi-focused. Responses to the project engaged creativity to articulate socio-cultural experience and preference (Luck \& Ewart, 2012) allowing a variety of responses to an open critical enquiry.

\section{References}


Anderson, J. (2004) Talking whilst walking: a geographical archaeology of knowledge. Area, Vol. 36, No. 3, pp 254-261

Bateson, G. (2002) Mind and nature: a necessary unity, Hampton Press, London

Batty, S. (2001) 'The Politics of Sustainable Development' in A.Layard, S. Davoudi and S. Batty (eds) 'Planning for a Sustainable Future' Spon Press, London, pp 19-32

Bohm, D. and David Peat, F. (2000) 'Science, Order, and Creativity' second edition, Routledge, London, pp 229-271

Brown, V. Harris, J and Russell, J. (2015) 'Tackling Wicked Problems: Through the Transdisciplinary Imagination’ Earthscan, London, pp 16-30

Cocchiarella, F. and Booth, P. (2015) Students as Producers: An 'X' Disciplinary Client-Based Approach to Collaborative Art, Design and Media Pedagogy, International Journal of Art and Design Education, Wiley, Vol. 34, No.3, pp 326-335

Deleuze, G., and Guattari, F., (2014) A Thousand Plateaus. Bloomsbury Academic, London, pp 1

Ellis, D. \& Thomas, M. (2001) Gorton Monestary, in eds. McKennan, G. et al. Manchester Architecture Papers. Manchester School of Architecture, Manchester UK

Fuad-Luke, A. (2007) 'Re-defining the purpose of (Sustainable) Design: Enter the Design enablers, Catalysts in co-design' in J.Chapman and N.Gant (eds) Designers Visionaries + Other Stories, Earthscan, London, pp 18-52

Freire, P. (1996) 'The Pedagogy of the Oppressed' Penguin Books, London, pp 11-22

Goodman, D. (1994) The Republic of Letters: A Cultural History of the French Enlightenment, Ithaca: Cornell University Press

Gunderson, L. and Holling, C. (2002) 'Panarchy: Understanding Transformations in Human and Natural Systems' Island Press, London, pp 3-22

Haley, D. (2008) The Limits of Sustainability: The Art of Ecology. Chapter in Eds. KAGAN, S. and KIRCHBERG, V. Sustainability: a new frontier for the arts and cultures. VAS-Verlag, Frankfurt, Germany

Haley, D. (2017) 'Undisciplinarity' and the Paradox of Education for Sustainable Development. In ed. Leal Filho, W. Handbook of Sustainable Science and Research. Series, Climate Change Management. Springer (IN PRESS) 
Haley, D., (2017a) Making Our Futures: Accidental Death of a Planet. Paper to Agents in the Anthropocene: Trans/disciplinary Practices in Art and Design Education Today. The Master of Education in Arts, Piet Zwart Institute, Rotterdam. (UNPUBLISHED)

Haley, D. Vargas, V.R. \& Ferrulli, P. (2016) Weaving the filigree: Paradoxes, opposites and diversity for participatory, emergent arts and design curricula on sustainable development. In W. Leal Filho et al. (Ed.), Handbook of Theory and Practice of Sustainable Development in Higher Education. Springer International Publishing

Jenkins, H. \& Deuze, M. (2008) Convergence Culture, Convergence London, vol. 14, no.1, p5

Keller, E., \& Fay, B. (2012) The face-to-face book: Why real relationships rule in a digital marketplace. Simon and Schuster

Knox, B. (1994) Backing into the Future: The Classical Tradition and its Renewl, W.W. Norton and Company, Inc. New York

Lakoff, G. \& Johnson, M. (1999) Philosophy in the Flesh: The Embodied Mind and its Challenge to Western Thought. Basic Books, New York

Langdown, A., \& Vargas, V. R. (2015) Integrating Sustainable Development within Teaching Fashion Education. In W. Leal Filho et al. (Ed.), Integrative Approaches to Sustainable Development at University Level, Springer International Publishing, pp 539-550

Luck, R. and Ewart, I. (2012) 'Towards a Living Future of Calm' in P.Rogers (ed) Articulating Design Thinking, Libri Publishing, pp 89-106

Lougee, C. (1976) Le Paradis des Femmes: Women, Salons and Social Stratification in Seventeenth Century France, Princeton University Press

Marsick, V.J. Maltbia, T.E. (2009) The transformative potential of action learning conversations. In: Mezirow, J. Taylor, E. W. Associates (Eds.), Transformative Learning in Practice: Insights from Community, Workplace and Higher Education. Jossey-Bass, San Fransico, pp 160-171

Meadows, D. H. (1999) Leverage Points: Places to intervene in the system, Sustainability Institute http://www.sustainer.org/?page_id=106 Retrieved 18 November 2016

Nicolescu, B. (2002) Manifesto of Transdisciplinarity. State University of New York Press, New York.

Quality Assurance Academy - QAA. (2014) Education for sustainable development: Guidance for UK higher education providers. Gloucester. Retrieved from 
http://www.qaa.ac.uk/en/Publications/Documents/Education-sustainable-developmentGuidance-June-14.pdf on the $1^{\text {st }}$ of June, 2016

Sierens, E. Vansteenkiste, M. Goossens, L. Soenens, B. \& Dochy, F. (2009) The synergistic relationship of perceived autonomy support and structure in the prediction of self-regulated learning, British Journal of Educational Psychology, Vol. 79, No. 1, pp 5768

Tilbury, D. Keogh, A. Leighton, A. Kent, J. (2005) A National Review of Environmental Education and its Contribution to Sustainability in Australia: Further and Higher Education. Australian Government Department of the Environment and Heritage and Australian Research Institute in Education for Sustainability (ARIES), Canberra.

Wahl, D.C. (2016) Designing Regenerative Cultures. Triarchy Press, Axminster, England

Walker, B. H. et al (2006) A handful of heuristics and some propositions for understanding resilience in social-ecological systems. Ecology and Society, vol. 11, no. 1, p.13 [online] URL: http://www.ecologyandsociety.org/vol11/iss1/art13/Retrieved 18 November 2016

Westley, F. Carpenter, S. Brock, W. Holling, C. and Gunerson, L. (2002) 'Why Systems of People and Nature are not just Social and Ecological Systems' in L. Gunderson and C. Holling 'Panarchy: Understanding Transformations in Human and Natural Systems' Island Press, London, pp 103-120

Author Biographies:

Fabrizio Cocchiarella MA(RCA) FHEA FRSA

Currently Programme Leader for BA(Hons) Three Dimensional Design at Manchester School of Art. Fabrizio's work as a lecturer, researcher and designer aims to inspire a new generation of critically aware creative professionals and contribute to shaping future scenarios for living. Fabrizio's specialism is routed in the production and manufacture of objects and installation projects utilizing the practice of Design as an interface in which to mediate and translate critical methodologies and commercial practices. Fabrizio is an Associate Fellow of the Higher Education Academy and the RSA (Royal Society for the Encouragement of the Arts, Manufacturing and Commerce).

\section{Valeria Ruiz Vargas}

Currently Education for Sustainable Development (ESD) Co-ordinator at Manchester Metropolitan University, Valeria Vargas leads the Environmental Management System policy area on ESD (i.e. Teaching and Learning). She regularly develops collaborative 
multidisciplinary, pedagogical and research projects. Valeria has expertise in the practice of appreciative inquiry approaches based on creative arts to facilitate change in social and environmental practices for multidisciplinary settings. For over 10 years, Valeria Vargas has applied creative arts including music and sculpture to facilitate resilience of (human and nonhuman) communities.

\section{Sally Titterington}

Associate Lecturer at Manchester Metropolitan University, MA unit 'Making Our Futures' in ecological arts and sustainable design, and a member of the research group LiFE. She works as a Designer and Media Artist producing art works from her own studio and collaborates with multidisciplinary studios; designing and producing products, media content and commissioned pieces for the creative, public and corporate industries. Since 2000, Sally is making an ongoing documentary and observational film 'Generous Acts' of the international furniture fair Salone del Mobile, Milan, Italy. She produces multimedia salons for international cultural exchange; creating soundscapes, film projections and collaborations with other artists from diverse creative fields.

\section{Dr David Haley HonFCIWEM RSA}

David Haley PhD HonFCIWEM FRSA, creates ecological artworks and publishes internationally to promote 'capable futures' that address our transformative challenges. $\mathrm{He}$ is a Visiting Professor at Zhongyuan University of Technology, China. At Manchester Metropolitan University, UK, he was a Senior Research Fellow, Director of the Ecology In Practice research group and led the MA unit in Making Our Futures - ecological arts and sustainable design. David is, also, Vice Chair of the CIWEM Art \& Environment Network, a member of UK MAB Urban Forum, Society for Ecological Restoration, Ramsar Culture Network Arts Group, and founding Trustee of Future's Venture Foundation. 